\title{
Using Instructor-Generated Video Lectures in Online Mathematics Courses Improves Student Learning
}

\author{
Jennifer S. Hegeman \\ Missouri Western State University
}

\begin{abstract}
Low retention rates in online freshman-level mathematics courses are a concern, especially at postsecondary institutions that serve academically unprepared students. The purpose of this study was to determine if student performance in an online College Algebra course that relies heavily on text-based multimedia tools can be improved by replacing publisher-generated educational resources with instructorgenerated video lectures. The original online College Algebra course placed the publisher-generated educational resources in the role of content provider by enabling all publisher-generated learning aids within the online homework system and treating instructor-generated educational materials as supplemental resources. In contrast, the redesigned online College Algebra course enhanced the course instructor's teaching presence by requiring students to complete instructor-generated guided note-taking sheets while watching instructor-generated video lectures, treating publisher-generated learning aids as supplemental resources by removing them from within the online homework system. Results indicate students who enrolled in a redesigned online College Algebra course that strategically placed the instructor in the role of content provider performed significantly better on both online and handwritten assessments than did students who enrolled in an online College Algebra course that placed the publishergenerated educational resources in that role.
\end{abstract}

\section{Introduction}

The performance-funding approach to financing higher education has concerned college and university administrators nationwide. State appropriations depend upon the institution's ability to meet or exceed performance indicators such as student retention and graduation rates. Given the evidence suggesting that withdrawal from college is associated with students' lack of success in "gatekeeper" courses such as entry-level college mathematics courses (Chen, 2013), it is no surprise faculty members 
who teach freshman-level mathematics are the first to be visited by administrators seeking lower failure and withdrawal rates. And, although $46 \%$ of chief academic officers at public institutions of higher education believe retaining students in the online environment is more difficult than retaining students in face-to-face formats (Allen \& Seaman, 2014), administrators continue to ask faculty to develop more online entry-level college mathematics courses.

As mathematics educators become more comfortable with emerging technologies that offer enhanced teaching and learning opportunities, they are more receptive to administrative requests for additional online general studies mathematics courses such as College Algebra and Elementary Statistics. Indeed, fully online general studies mathematics courses have become more widespread, in part due to the development of text-based, interactive multimedia tools such as ALEKS, MyMathLab, and Enhanced WebAssign. As noted on their product websites, these text-based tools have been adopted by all major academic publishers and integrated with hundreds of textbooks, serving thousands of educational institutions and millions of students (ALEKS, 2014; MyLab and Mastering, 2014; WebAssign, 2014). Students enrolled in mathematics courses utilizing these text-based tools have access to an $e$-book, an online homework system, and a variety of embedded publisher-generated learning aids (e.g., video lectures, animations, completed examples, and guided tutorials). Mathematics faculty who adopt these text-based tools for their face-to-face and online courses have access to an online course management system that provides them with a complete set of relevant mathematics exercises from which to create online assessments, in addition to a gradebook that monitors student success and time on task. Having access to comprehensive online educational resources and a course management system specific to mathematics has been instrumental in convincing hesitant mathematics educators to try teaching in the online environment.

Unfortunately, low retention rates in online freshman-level mathematics courses are a concern, especially at postsecondary institutions that serve academically unprepared students (Xu \& Jaggars, 2011; Zavarella \& Ignash, 2009). In a study of community college students enrolled in developmental mathematics courses, Zavarella and Ignash (2009) observed that students enrolled in computer-based courses were more likely to withdraw than students enrolled in lecture-based courses. Similarly, Xu and Jaggars (2011) found that community college students enrolled in online freshman-level mathematics courses experienced higher attrition rates and were less likely to earn grades of $\mathrm{C}$ or better than those students enrolled in face-to-face offerings. Both studies indicated that online instruction, as it was structured in these cases, may not be as effective as face-to-face instruction for students who are unprepared for freshman-level mathematics courses.

Regardless of the issues with reduced retention, students in higher education continue to enroll in online courses. According to the latest report on the status of online education from the Babson Survey Research Group, approximately 33.5\% of all college students enroll in at least one online class (Allen \& Seaman, 2014). Furthermore, while the annual growth rate of overall enrollment in higher education from fall 2011 to fall 2012 was $1.2 \%$, the annual growth rate of online enrollment in higher education over the same time period was $6.1 \%$. Given that online education continues to play an important role in institutions of higher education, it is imperative that mathematics faculty determine whether or not instruction provided in online freshman-level mathematics courses is meeting students' needs. If it is determined that online mathematics instruction is ineffective, can mathematics faculty identify and incorporate course design techniques that encourage student engagement, persistence, and learning?

\section{Literature Review}

Mathematics anxiety and negative attitudes towards mathematics can have a negative impact on student success in university-level mathematics courses. Nunez-Pena and Suarez-Pellicioni (2013) observed students who failed a mathematically challenging university course had higher mathematics 
anxiety and higher course anxiety than students who passed the university course. Furthermore, they noted students who failed the course had lower self-confidence in and motivation toward mathematics than students who passed. While such attitudinal and emotional factors can impact student engagement and persistence in mathematics, Furner and Gonzalez-DeHass (2011) indicated creating a masteryoriented classroom can help reduce these anxieties. Specifically, they recommended teachers establish a class climate that emphasizes thinking rather than rote memorization, encourages students to ask questions, and allows students to engage in activities that allow them to learn from and correct their mistakes.

Mathematics educators interested in creating a class climate that not only reduces student anxieties, but also improves student learning outcomes, have experimented with text-based, interactive multimedia tools such as ALEKS and MyMathLab (Aichele, Francisco, Utley, \& Wescoatt, 2011; Brewer, 2009; Klein, 2005; Taylor, 2008; Xu, Meyer, \& Morgan, 2008). While both web-based tools emphasize content mastery and provide students with immediate feedback that offers suggestions for where student errors may have occurred in the solution process, best practice in the use of these technologies in mathematics courses has yet to be determined. Taylor (2008) concluded that college freshmen enrolled in developmental mathematics courses using ALEKS experienced a reduction in anxiety and an improvement in attitude toward mathematics. Furthermore, results indicated that some students' mathematics achievement was also improved. Similarly, Xu et al. (2008) noted that students in a graduate-level educational statistics course using a blended learning approach and ALEKS performed better than students enrolled in a more traditional course. However, $\mathrm{Xu}$ et al. also discovered that lowand medium-performing students were more likely to perceive a misalignment between the course textbook and the online multimedia tools. Some students admitted to intentionally "working the system" in order to reduce the amount of time spent engaging with the online tools. And, although students may have appreciated being able to continuously review the material in the online environment, they acknowledged the importance of observing the instructor as problem solutions were being presented, as well as the importance of having their own work evaluated by the instructor so that misconceptions could be more accurately identified and corrected.

Similar issues have been noted in freshman-level mathematics courses that use MyMathLab (Aichele, Francisco, Utley, \& Wescoatt, 2011; Brewer, 2009; Klein, 2005). Brewer (2009) found students who enrolled in face-to-face College Algebra courses that used MyMathLab for homework experienced frustration not only with the software's inability to provide more informative feedback when answers were incorrect, but also the level of precision required by the software in order to earn full credit. Overall, the mathematics achievement of students using online homework was comparable to the mathematics achievement of students using textbook homework. However, students who used MyMathLab for homework and who were academically unprepared or repeating the course did outperform their counterparts who used textbook homework. In a second study that explored the use of MyMathLab in College Algebra, Klein (2005) concluded that supplementing traditional College Algebra instruction with the computer-assisted instruction embedded within MyMathLab did not result in a statistically significant improvement in student achievement, nor did it improve student attitude toward mathematics. A third study by Aichele et al. (2011) focused on students' perceptions of the usefulness of the educational resources embedded in MyMathLab. Both Klein (2005) and Aichele et al. (2011) noted that students preferred the View an Example and Help Me Solve This features embedded within MyMathLab. Furthermore, according to Aichele et al. (2011), students indicated that they preferred these two features because they provided step-by-step procedures for the solution process, with the View an Example feature being the most preferred since it required less work on the part of the student. Few students indicated that these features enhanced their conceptual understanding of the reasoning behind the solution process. In addition, the majority of students surveyed considered the publisher-generated videos to be one of the least beneficial resources since watching them required more time on the part of the student. 
Research indicates teaching presence in the online classroom, as defined by Anderson, Rourke, Garrison, and Archer (2001), plays an important role in the development of a class climate that provides students with a rewarding educational experience. In a study of online student satisfaction, all three categories of teaching presence-design and organization, facilitating discourse, and direct instructionwere found to be highly correlated with course satisfaction and student perception of learning (Shea, Pickett, \& Pelz, 2003). Data collected by Hosler and Arend (2012) indicated that online students believed teaching presence influences their critical thinking. In yet another study, teaching presence was found to be a strong predictor of student affective learning, motivation, and perceived cognition in online undergraduate and graduate classes (Baker, 2010).

As college and university faculty across disciplines have gained experience in teaching and learning in the online environment, intentional course design techniques and instructional activities that tend to promote teaching presence and student motivation have surfaced. Lehman and Conceição (2014) noted that one such course design technique involves dividing the course content into pieces called "chunks" and carefully arranging these chunks into modules having a similar structure. Designing the online course in this manner reduces cognitive overload and allows students to focus on the content being presented. Other intentional design techniques noted in online teaching literature include anticipating student needs and addressing them in orientation activities, providing clear expectations and wellestablished deadlines early in the course, and providing prompt and personalized feedback (Fish \& Wickersham, 2009; Jaggars, Edgecombe, \& Stacey, 2013; Lehman \& Conceição, 2014).

While online instructors across disciplines agree that the implementation of intentional course design techniques can enhance teaching presence and improve student engagement and persistence, the specific design techniques and instructional activities that best support the online learning environment may differ by discipline. In an effort to identify specific instructor behaviors used to promote teaching presence in online science courses, Stone and Chapman (2006) engaged in formal interviews with three undergraduate science instructors, each having at least five years of online teaching experience. Based on the interview data, Stone and Chapman were able to define instructor presence within three constructs: course content, instructor's role, and student needs. The instructors who were interviewed believed that they were able to create and sustain teaching presence in online science courses by placing themselves in the role of content provider (i.e., the individual who has ownership of and control over the course content, and the ability to make content changes and updates), as well as the role of facilitator of learning; incorporating their own personal educational materials, as well as a variety of multimedia tools; maintaining instructor-student interaction by supplying prompt and frequent feedback; providing an effective student support structure; and organizing content and structuring the course to allow for selfdirected learning.

Just as instructors differ in their perceptions of what design techniques and instructional activities are most appropriate for teaching and learning their discipline in an online environment, students enrolled in online courses also differ in their perceptions of what instructional activities best support their learning needs. In an analysis of student behaviors in online general studies courses from various disciplines, Finnegan, Morris, and Lee (2009) discovered that while students must be willing to spend time engaging in online activities if they are to be successful, the online activities they use to engage in the learning process may differ by discipline. Students who successfully completed online English, communication, and social science courses spent more of their time participating in online discussions (e.g., posting their own questions, reading and replying to other students' posts), while students who successfully completed online science and mathematics courses spent more of their time viewing content pages and posting their own questions. Simonds and Brock (2014), in an exploration of student learning preferences in online graduate education courses, concluded that while younger students preferred interactive online learning activities, older students preferred to learn from recorded video lectures. Given the positive impact of providing recorded video lectures for asynchronous viewing in face-to-face undergraduate courses that 
have significant mathematical content (Brecht, 2012; Cascaval, Fogler, Abrams, \& Durham, 2008), it may be that students enrolled in online mathematics and science courses would also benefit from the inclusion of video lectures as instructional activities.

Although mathematics educators have experimented with the use of text-based multimedia tools such as ALEKS and MyMathLab in the teaching and learning of freshman-level mathematics, additional research is needed to determine the most effective way to use these tools in the online general studies mathematics course. Since text-based tools such as MyMathLab provide students access to comprehensive educational resources, can these publisher-generated resources, by themselves, adequately strengthen students' conceptual understanding to ensure student success? Does the availability of the publisher-generated educational resources diminish the visibility of the course instructor's teaching presence, and if so, what can course instructors do to re-establish their teaching presence? If students have a tendency to take shortcuts to reduce time on task, is it best to restrict the publisher-generated educational resources that are available to them within the online homework system? If certain publishergenerated educational resources are disabled within the online homework system, what instructorgenerated educational resources should be provided in their place to facilitate student learning? The purpose of this study was to determine if an online College Algebra course relying heavily on publishergenerated educational resources can be redesigned to make the course instructor's teaching presence more visible and hence, better meet the needs of unprepared students. Consequently, the study focused on the following research questions:

1. Can student performance in an online College Algebra course that relies heavily on textbased multimedia tools be improved by replacing the publisher-generated educational resources with instructor-generated video lectures?

2. Can student attrition in an online College Algebra course that relies heavily on text-based multimedia tools be reduced by replacing the publisher-generated educational resources with instructor-generated video lectures?

3. Can teaching presence in the form of instructor-generated video lectures serve as a predictor of student success in online College Algebra?

\section{Method}

\section{Participants}

Study participants included students who self-enrolled in the online College Algebra courses offered at an open-enrollment university in the Midwestern United States over a two-year period. All courses were assigned to the author and were available for enrollment throughout the regular registration periods. The chairperson of the university's Institutional Research Board informed the author that standard educational practices were exempt from the IRB approval requirement. Therefore, since the author was simply teaching the online course differently than how it had been taught previously, IRB approval was not required. This study is limited by the fact that students were not randomly assigned to the courses included in the analysis, but perhaps strengthened by the fact that the author has been the only faculty member assigned to the online offerings of College Algebra at this university.

Sixty-nine students enrolled in the original online courses offered during the first year (i.e., Spring 2012 and Fall 2012). Eighty-seven students enrolled in the redesigned online courses offered during the second year (i.e., Fall 2013 and Spring 2014). Although students are not required to have documented ACT scores on file to enroll in the university, the current course prerequisite for College Algebra at the university is an ACT Math sub-score of at least 20, or the equivalent (i.e., a grade of C or better in the university's developmental mathematics courses). Given the strong positive relationship 
between ACT scores and college student success (Bleyaert, 2010; Richardson, Abraham, \& Bond, 2012), students having no documented ACT scores on file with the university were deleted from the samples. Furthermore, students who remained on the course roster but did not actually complete the course (i.e., they stopped attending the course but did not officially withdraw) were also deleted. Table 1 provides an overview of the student profiles included in all statistical analyses.

Table 1. Online College Algebra Student Profiles, by Course Design

\begin{tabular}{lll}
\hline & $\begin{array}{l}\text { Original } \\
\text { (Spring 2012, Fall 2012) }\end{array}$ & $\begin{array}{l}\text { Redesigned } \\
\text { (Fall 2013, Spring 2014) }\end{array}$ \\
\hline Number of students & 51 & 44 \\
\hline Mean ACT Math & $17.76(S D=2.43)$ & $18.52(S D=3.19)$ \\
\hline Mean Age & $23.47(S D=6.74)$ & $26.09(S D=9.02)$ \\
\hline Gender & Female 67\% & Female 68\% \\
& Male 33\% & Male 32\% \\
\hline \multirow{3}{*}{ Student Rank } & Freshman 35\% & Freshman 32\% \\
& Sophomore 26\% & Sophomore 27\% \\
& Junior 26\% & Junior 18\% \\
& Senior 14\% & Senior 23\% \\
\hline Off-Campus & $86 \%$ & $86 \%$ \\
\hline Repeating Course & $35 \%$ & $34 \%$ \\
\hline
\end{tabular}

While the mean ACT Math sub-score for the redesigned course was higher than the mean ACT Math sub-score for the original course, the difference was not statistically significant $\left(H_{A}: \mu_{1} \neq \mu_{2} ; t(79)=-\right.$ 1.29; $p=0.202)$. A similar difference was noted in the overall campus mean ACT Math sub-scores during the two time periods (i.e., 19.81 and 20.07, respectively). A comparison of the campus mean ACT Math sub-scores to the mean ACT Math sub-scores in the online offerings of College Algebra indicates that the online offerings of College Algebra at this open-enrollment university tend to attract mathematically weaker students.

The mean age of students enrolled in the redesigned course was higher than the mean age of students enrolled in the original course, but the difference was not statistically significant $\left(H_{A}: \mu_{1} \neq \mu_{2}\right.$; $t(78)=-1.58 ; p=0.117)$. Comparisons of student differences in gender $\left(\chi^{2}(1, N=95)=0.025 ; p=0.875\right)$, student rank $\left(\chi^{2}(3, N=95)=1.754 ; p=0.625\right)$, location of residence, and whether or not the College Algebra course was being repeated $\left(\chi^{2}(1, N=95)=0.015 ; p=0.902\right)$, also indicated no statistically significant differences. Furthermore, although approximately $35 \%$ of the students enrolled during the four-semester period were repeating College Algebra, none of the students were repeating the online offering of the course.

While this study is limited by the fact that students were not randomly assigned to the courses included in the analysis, the evidence suggests the two samples were independent and drawn from the same population, and thus, may be considered equivalent for the purposes of this study.

\section{Technology}

All online courses over the two-year period were required to have access to MyMathLab, an online multimedia educational system designed by Pearson Education to accompany its published mathematics textbooks. Students enrolled in the redesigned online College Algebra course were also required to use Moodle, the university's online learning management system. All instructor-generated video lectures in the redesigned course were created by projecting PowerPoint presentations onto a SMART Podium Annotation Monitor and recording all handwritten solutions and oral explanations with 
Panopto, a lecture capture system. Instructor-generated explanations for how to use the graphing calculator were also recorded using Panopto and a document camera.

\section{Course Design}

Students enrolled in both the original online College Algebra course and the redesigned online College Algebra course were required to have access to the multimedia educational system that accompanies the course textbook adopted by the university. This text-based multimedia educational system provided students with access to the $e$-book (i.e., an electronic copy of the textbook) and an online homework system.

Original Online College Algebra Course, Spring 2012 and Fall 2012. In the original online College Algebra course, the primary sources for course content and instruction were the publishergenerated learning aids enabled within the online homework exercises provided by the text-based multimedia educational system. Each exercise within the online homework system offered students a variety of publisher-generated learning aids to assist them in obtaining the correct answer for that particular exercise. Publisher-generated learning aids available for each homework exercise included a 15-30 minute video lecture provided by one of five different lecturers, an animation, a completed example, a guided tutorial, a link to the $e$-book, and a mechanism for asking the instructor a question via email. Both the video lecture and the animation provided a general overview of the topic being assessed by the given homework exercise, while the completed example provided a step-by-step solution for a problem identical in type, difficulty level, and conceptual scope. The guided tutorial assisted students in working the given homework exercise, requiring that the student then complete an algorithmicallygenerated identical problem on their own to earn credit for that exercise.

The course instructor's teaching presence in the original online College Algebra course consisted of supplemental instructor-generated educational resources (i.e., typed lecture notes, offline exam review materials, and video recordings of handwritten solutions to problems included in the offline exam review materials) uploaded into the text-based multimedia educational system and available on the first day of the semester, instructor-student interaction in the form of frequent instructor-initiated group email messages (at least one per week) and periodic individualized course status email messages, and instructorstudent interaction in the form of prompt email responses to student questions about content (generally within 12 hours). The importance of email as the main mode of communication was emphasized frequently at the start of each semester. Except for the video recordings of handwritten solutions to problems included in the offline exam review materials, instructor-student interaction was limited to typed communication in the form of typed lecture notes or email correspondence.

In the original online College Algebra course, students were not required to engage with any specific educational resource. They were given the freedom to decide whether or not to engage with a publisher-generated learning aid associated with an online homework exercise or an instructor-generated resource.

Redesigned Online College Algebra Course, Fall 2013 and Spring 2014. In the redesigned online College Algebra course, the primary sources for course content and instruction were instructorgenerated video lectures and coordinated note-taking sheets that were organized within the universityadopted course management system (i.e., outside of the publisher's multimedia educational system). The course content was assembled into five units, each unit consisting of five to six similarly-structured modules, a course design technique that has been shown to promote student motivation (Lehman \& Conceição, 2014). Each unit of modules became visible to the students only when it was time to begin working on that unit. The offline exam review materials provided by the instructor in the original online College Algebra course were also provided in the redesigned College Algebra course and were attached to the end of each unit. 
Each module consisted of a set of instructor-generated guided note-taking sheets and at most five instructor-generated video lectures, each 5 - 40 minutes in length, with $65 \%$ of the videos being less than 20 minutes and $91 \%$ of the videos being less than 30 minutes. The content of the note-taking sheets was carefully coordinated with the content of the instructor-generated video lectures. Students were required to print off the note-taking sheets and complete them while watching the corresponding PowerPoint presentations that provided complete instruction for the algebraic concepts being addressed in that module and solutions to several relevant examples, emphasizing throughout the importance of understanding why each step in a solution is being performed. All 91 video lectures (i.e., over 26 hours of recorded lecture) were created in an empty room using an annotation monitor, a document camera, and a lecture capture system. As the instructor displayed the PowerPoint slides, concepts were discussed and examples were completed directly on the annotation monitor, comparable to the instruction provided in the face-to-face environment. All handwritten solutions and verbal explanations were recorded by the lecture capture software, allowing students the opportunity to pause, rewind, fast forward, and replay as needed. The note-taking sheets were graded on completion four times during the semester and returned to the student.

A link to the text-based multimedia educational system was included within the universityadopted course management system. While the original online College Algebra course enabled all of the publisher-generated learning aids within the online homework exercises provided by the text-based multimedia educational system, the redesigned course treated the publisher-generated learning aids as supplemental resources that accompany the course textbook. That is, the only publisher-generated learning aids enabled within the online homework in the redesigned course were the link to the $e$-book and the mechanism for asking the instructor a question via email. Although the publisher-generated video lectures, completed examples, and guided tutorials were not enabled within the homework, these learning aids were accessible via the online version of the textbook, a fact that was not publicized by the course instructor. The online version of the textbook was different from the $e$-book in that it included embedded links to not only relevant publisher-generated video lectures, but also interactive examples that provide access to other publisher-generated learning aids (i.e., completed examples and guided tutorials). While the $e$-book could be accessed within the homework system, the online version of the textbook with the embedded learning aids was only accessible when the homework system was closed.

At the beginning of each offering of the redesigned online College Algebra course, the instructor emphasized the importance of referring to the instructor-generated videos and their corresponding notetaking sheets when questions emerged while completing homework assignments. Students needing additional assistance beyond what the videos and note-sheets could provide were encouraged to email the instructor a detailed question. The instructor also encouraged students in the redesigned course to use their smartphones to send pictures of their work to the instructor rather than typing their questions, as was the norm in the original course. This approach made it easier for students to clearly communicate mathematical symbolism and easier for the instructor to locate student errors.

The course instructor's teaching presence in the redesigned online College Algebra course consisted of instructor-generated video lectures and their respective note-taking sheets (as well as the offline exam review materials) organized within the university-adopted course management system, instructor-student interaction in the form of frequent instructor-initiated group email messages (at least one per week) and periodic individualized course status email messages, and instructor-student interaction in the form of prompt email responses to student-initiated questions about content (generally within 12 hours). Again, the importance of email as the main mode of communication was emphasized frequently at the start of each semester.

In the redesigned online College Algebra course, students were required to complete guided notetaking sheets while watching over 26 hours of instructor-generated video lectures. Although students were given the freedom to decide whether or not to engage with a publisher-generated learning aid, these learning aids were only accessible outside of the homework system. 
Table 2 summarizes how the original online College Algebra course compares to the redesigned online College Algebra course in terms of how the course instructor's teaching presence was facilitated according to the eight descriptors identified by Stone and Chapman (2006).

Table 2. Efforts to Facilitate Course Instructor’s Teaching Presence, by Course Design

\begin{tabular}{|c|c|c|}
\hline & Original & Redesigned \\
\hline $\begin{array}{l}\text { 1. Via the instructor's role as } \\
\text { content provider and subject } \\
\text { matter expert }\end{array}$ & $\begin{array}{l}\text { Type-set } \quad \text { lecture } \\
\text { (201 pages) (Optional) }\end{array}$ & 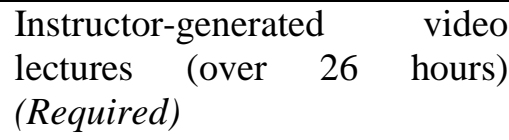 \\
\hline $\begin{array}{l}\text { 2. By using materials unique to } \\
\text { the instructor }\end{array}$ & $\begin{array}{l}\text { Type-set } \quad \text { lecture } \\
\text { (201 pages) (Optional) }\end{array}$ & $\begin{array}{l}\text { Instructor-generated } \\
\text { lectures (over } 26 \\
\text { (Required) }\end{array}$ \\
\hline $\begin{array}{l}\text { 3. Through the creation of one's } \\
\text { own learning objects }\end{array}$ & $\begin{array}{l}\text { Type-set lecture } \\
\text { (201 pages) (Optional) }\end{array}$ & $\begin{array}{l}\text { Guided note-taking sheets (182 } \\
\text { pages) graded on completion } \\
\text { (Required) }\end{array}$ \\
\hline $\begin{array}{l}\text { 4. By designing an effective } \\
\text { student support structure }\end{array}$ & $\begin{array}{l}\text { Offline and online review } \\
\text { materials }\end{array}$ & $\begin{array}{l}\text { Offline and online review } \\
\text { materials }\end{array}$ \\
\hline $\begin{array}{l}\text { 5. Through the instructor's role as } \\
\text { facilitator of learning }\end{array}$ & $\begin{array}{l}\text { Instructor-initiated weekly } \\
\text { group email announcements; } \\
\text { Instructor responses to student- } \\
\text { initiated questions }\end{array}$ & $\begin{array}{l}\text { Instructor-initiated weekly } \\
\text { group email announcements; } \\
\text { Instructor responses to student- } \\
\text { initiated questions }\end{array}$ \\
\hline $\begin{array}{l}\text { 6. By implementing high } \\
\text { instructor immediacy behaviors in } \\
\text { feedback }\end{array}$ & $\begin{array}{l}\text { Email responses to student } \\
\text { questions (generally within } 12 \\
\text { hours) }\end{array}$ & $\begin{array}{l}\text { Email responses to student } \\
\text { questions (generally within } 12 \\
\text { hours) }\end{array}$ \\
\hline $\begin{array}{l}\text { 7. Through the use of a variety of } \\
\text { media formats }\end{array}$ & $\begin{array}{l}\text { Publisher-generated learning } \\
\text { aids enabled within online } \\
\text { homework }\end{array}$ & $\begin{array}{l}\text { Publisher-generated learning } \\
\text { aids accessible within online } \\
\text { textbook but disabled within } \\
\text { online homework }\end{array}$ \\
\hline $\begin{array}{l}\text { 8. By organizing content and } \\
\text { structuring the course for self- } \\
\text { directed learning }\end{array}$ & $\begin{array}{l}\text { Course materials organized } \\
\text { within publisher-provided } \\
\text { multimedia system; } \\
\text { Homework assignments and } \\
\text { course materials visible from } \\
\text { first day }\end{array}$ & $\begin{array}{l}\text { Course materials organized } \\
\text { outside of publisher-provided } \\
\text { multimedia system; } \\
\text { Homework assignments and } \\
\text { course materials become visible } \\
\text { when unit begins }\end{array}$ \\
\hline
\end{tabular}

Adapted from Stone et al. (2006)

As noted in Table 2, the aspects of teaching presence related to facilitating discourse were identical between the two design models. However, the two design models differed in how they facilitated the course instructor's teaching presence in relation to design and organization, and direct instruction.

\section{Course Grading Policies and Assessment Components}

Course grades in the original online College Algebra course were computed as follows: Online Homework (10\%), Online Quizzes (10\%), Online Exams (30\%), Handwritten Midterm Exam (25\%), and 
Handwritten Common Comprehensive Final Exam (25\%). In the redesigned online College Algebra course, the Online Homework was reduced to $5 \%$ of the overall course grade, with Class Participation (i.e., the note-taking sheets graded on completion) accounting for the remaining $5 \%$. The weights of all other assessment components were the same.

The online assessment components in both the original and the redesigned courses were intentionally structured to create a class climate that emphasizes a mastery-oriented approach to learning. Prior to the due date for a given online homework assignment, students had unlimited attempts to correctly answer each question. During each two-day online quiz window, students were allowed to take the quiz up to three times. During each two-day online exam window, students were allowed to take the exam only once.

The problems selected for inclusion on all online assessments (i.e., homework, quizzes, and exams) were identical in both the original and the redesigned courses. The online quizzes and online exams were non-proctored assessments, while the handwritten midterm exam and handwritten final exam were proctored by either the instructor or by an institution listed as a participant of the Consortium of College Testing Centers.

Beginning in the Spring 2012 semester, the university mathematics department implemented a handwritten common final exam to be given in all College Algebra offerings. The common final exam was given in both the original and the redesigned courses. Associated with this common final exam is a policy that requires students to earn at least $50 \%$ on the exam in order to earn a passing grade in the course. The final exam consists of 20 typical College Algebra problems. Each problem is randomly selected from a pool of 2-3 algorithmically-generated problems that are similar in difficulty level and conceptual scope. In an effort to better prepare the online students for the format of the high-stakes final exam, the instructor created the handwritten midterm exam to include problems comparable to those that might appear on the common final exam. The midterm exam was also given in both the original and the redesigned courses. The handwritten midterm exam for Spring 2012 served as the model for the midterm exams given during the Fall 2012, Fall 2013, and Spring 2014. That is, questions selected for inclusion on the midterm exams after the initial Spring 2012 semester were similar in difficulty level and conceptual scope to those questions on the original midterm exam. To maintain consistency in the grading of the handwritten exams given in both the original and redesigned courses, detailed grading rubrics were followed after removing all student names.

\section{Time on Task}

Given the tendency for successful online students to spend more time engaging with online learning activities (Finnegan, Morris, \& Lee, 2009), a measurement for time on task was determined for all enrolled students.

Original Online College Algebra Course, Spring 2012 and Fall 2012. Time on task (in hours) for each student in the original online College Algebra course was measured by the time tracking feature of the text-based multimedia educational system that monitors student activity within online assessments (i.e., online homework, online quizzes, and online exams). Consequently, when a student chose to engage with a publisher-generated learning aid (i.e., a publisher-generated video, an animation, a completed example, a guided tutorial, or the $e$-book) while working on online homework, the time spent interacting with the learning aid was included in the measurement of time on task. Time spent engaging with a publisher-generated learning aid outside of the online homework assignment, time spent reviewing past online assessments, and time spent working offline were not included in this measurement.

Redesigned Online College Algebra Course, Fall 2013 and Spring 2014. Time on task (in hours) for each student in the redesigned online College Algebra course consisted of the sum of two 
quantities - an approximation for the time spent watching the instructor-generated video lectures and the time on task as measured by the time tracking feature of the text-based multimedia educational system. When the video lectures were inadvertently made public, the lecture capture system did not retain user statistics, and hence, an approximation for the time spent watching the instructor-generated video lectures was computed. Since the class participation grade for the redesigned course was determined by the percentage of the note-taking sheets completed, and the note-taking sheets could not be completed without watching the video lectures, the time spent watching the instructor-generated video lectures was approximated by multiplying the total number of hours in the video collection (i.e., 26 hours) by the class participation grade.

As with the original online College Algebra course, the time tracking feature of the text-based multimedia educational system monitored student activity within online assessments (i.e., online homework, online quizzes, and online exams). When a student chose to engage with the $e$-book (i.e., the only publisher-generated learning aid enabled within the online homework in the redesigned College Algebra course) while working on online homework, the time spent interacting with the $e$-book was included in the measurement of time on task. Time spent engaging with a publisher-generated learning aid outside of the online homework assignment, time spent reviewing past online assessments, and time spent working offline were not included in this measurement.

\section{Data Analysis}

Student profile data suggests that the two samples were independent and drawn from the same population, and thus, may be considered equivalent for the purposes of this study. The level of significance used in all data analysis was $\alpha=0.05$.

Student Performance. To address the question of whether student performance in an online College Algebra course relying heavily on text-based multimedia tools can be improved by replacing the publisher-generated educational resources with instructor-generated video lectures, five different onetailed $t$-tests for independent samples were used to compare the original online College Algebra course to the redesigned College Algebra course on all assessment components common to both courses: online homework, online quizzes, online exams, handwritten midterm exam, and handwritten final exam.

Online Homework. The student overall score on online homework was determined by computing the percentage correct on 25 equally-weighted homework assignments.

Online Quizzes. The student overall score on online quizzes was determined by computing the percentage correct on five equally-weighted quizzes.

Online Exams. The student overall score on online exams was determined by computing the percentage correct on three equally-weighted exams.

Handwritten Midterm Exam and Handwritten Final Exam. Student scores on both handwritten exams were determined by awarding points according to detailed grading rubrics, summing all points earned, and computing the corresponding percentage.

Time on Task. A t-test for independent samples was used to compare the time on task (in hours) for students in the original online College Algebra course with the time on task for students in the redesigned College Algebra course.

Course Grade Distributions and Student Attrition. Given that many university degree programs require a grade of $\mathrm{C}$ or better in general studies mathematics, letter grades of $\mathrm{A}, \mathrm{B}$, and $\mathrm{C}$ were considered passing grades in this analysis. A chi-square test was used to compare the overall course pass rate of the original online College Algebra course to the overall course pass rate of the redesigned College 
Algebra course. Similarly, a second chi-square test was used to compare overall course pass rates when all 156 enrolled students were taken into consideration.

The student attrition rate was defined to be the percentage of students officially withdrawing from the course. To address the question of whether student attrition in an online College Algebra course relying heavily on text-based multimedia tools can be reduced by replacing the publisher-generated educational resources with instructor-generated video lectures, a chi-square test was used to compare the student attrition rate of the original online College Algebra course to the student attrition rate of the redesigned College Algebra course. Similarly, a second chi-square test was used to compare student attrition rates when all 156 enrolled students were taken into consideration.

Teaching Presence as a Predictor of Student Success. To address the question of whether teaching presence in the form of instructor-generated video lectures can serve as a predictor of student success in online College Algebra, a multiple regression analysis was performed. The independent variables for the regression model included design (original $=0$, redesigned $=1$ ), time on task (in hours), and ACT Math sub-scores (1-36). The dependent variable was student learning as measured by the overall course percentage computed according to the course grading policies outline in the course syllabi.

\section{Results}

\section{Assessment Components}

Online Homework. Results indicated student overall scores on online homework in the original online College Algebra course $(M=83.43, S D=16.95)$ were not statistically significantly different from student overall scores on online homework in the redesigned online College Algebra course $(M=82.13$, $S D=17.12 ; t(54)=0.29, p=0.613$, one-tailed).

Online Quizzes. Results indicated student overall scores on online quizzes in the original online College Algebra course $(M=67.41, S D=23.55)$ were statistically significantly lower than student overall scores on online quizzes in the redesigned online College Algebra course $(M=76.63, S D=12.95 ; t(45)=-$ 1.86, $p=0.035$, one-tailed). The magnitude of the difference in means was small (mean difference $=-9.22$, 95\% upper bound: $\left.-0.87 ; r^{2}=0.06\right)$.

Online Exams. Again, results indicated student overall scores on online exams in the original online College Algebra course $(M=64.47, S D=21.44)$ were statistically significantly lower than student overall scores on online exams in the redesigned online College Algebra course $(M=78.25, S D=12.40$; $t(47)=-3.01, p=0.002$, one-tailed). The magnitude of the difference in means was moderate (mean difference $=-13.78$, 95\% upper bound: $-6.09 ; r^{2}=0.16$ ). That is, course design explains $16 \%$ of the variation in student overall scores on online exams.

Handwritten Midterm Exam. Student scores on the handwritten midterm exam in the original online College Algebra course $(M=50.00, S D=21.84)$ were statistically significantly lower than student scores on the handwritten midterm exam in the redesigned online College Algebra course $(M=65.75$, $S D=15.79 ; t(52)=-3.14, p=0.001$, one-tailed). The magnitude of the difference in means was moderate (mean difference=-15.75, 95\% upper bound: $-7.36 ; r^{2}=0.16$ ). That is, course design explains $16 \%$ of the variation in student scores on the handwritten midterm exam.

Handwritten Final Exam. Student scores on the handwritten final exam in the original online College Algebra course $(M=44.93, S D=26.36)$ were statistically significantly lower than student scores on the handwritten final exam in the redesigned online College Algebra course $(M=59.94, S D=17.29$; $t(50)=-$ 2.56, $p=0.007$, one-tailed). The magnitude of the difference in means was moderate (mean difference $=-$ 15.01 , 95\% upper bound: $-5.20 ; r^{2}=0.12$ ). That is, course design explains $12 \%$ of the variation in student scores on the handwritten final exam. 


\section{Time on Task}

Results indicated that while the mean number of hours spent on task by students in the original online College Algebra course $(M=60.80, S D=52.29)$ was lower than the mean number of hours spent on task by students in the redesigned online College Algebra course $(M=73.78, S D=32.99)$, the difference was not statistically significant $(t(49)=-1.13, p=0.132$, one-tailed).

Table 3 summarizes the results obtained in the comparison of the original online College Algebra course and the redesigned online College Algebra course on all assessment components and time on task.

Table 3. Computed Means for Assessment Components and Time on Task, by Course Design

\begin{tabular}{lllll}
\hline & $\begin{array}{l}\text { Original } \\
(N=51)\end{array}$ & $\begin{array}{l}\text { Redesigned } \\
(N=44)\end{array}$ & $p$ & $r^{2}$ \\
\hline Online Homework & $83.43 \%$ & $82.13 \%$ & 0.613 & na \\
Online Quizzes & $67.41 \%$ & $76.63 \%$ & 0.035 & 0.06 \\
Online Exams & $64.47 \%$ & $78.25 \%$ & 0.002 & 0.16 \\
Handwritten Midterm & $50.00 \%$ & $65.75 \%$ & 0.001 & 0.16 \\
Handwritten Final & $44.93 \%$ & $59.94 \%$ & 0.007 & 0.12 \\
Time on Task & $60.80 \mathrm{hrs}$ & $73.78 \mathrm{hrs}$ & 0.132 & na \\
\hline
\end{tabular}

\section{Course Grade Distributions and Student Attrition}

Overall course grade distributions, sorted by course design, are provided in Table 4.

Table 4. Grade Distributions, by Course Design

\begin{tabular}{llll}
\hline & $\begin{array}{l}\text { Original } \\
(N=51)\end{array}$ & $\begin{array}{l}\text { Redesigned } \\
(N=44)\end{array}$ & Difference \\
\hline A & $5.88 \%$ & $4.55 \%$ & -1.34 \\
$\mathrm{~B}$ & $5.88 \%$ & $6.82 \%$ & 0.94 \\
$\mathrm{C}$ & $3.92 \%$ & $27.27 \%$ & 23.35 \\
Grades of A, B, and C together & $15.69 \%$ & $38.64 \%$ & 22.95 \\
$\mathrm{D}$ & $15.69 \%$ & $11.36 \%$ & -4.32 \\
$\mathrm{~F}$ & $27.45 \%$ & $11.36 \%$ & -16.09 \\
$\mathrm{~W}$ & $41.18 \%$ & $38.64 \%$ & -2.54 \\
\hline
\end{tabular}

The course pass rate for the redesigned online College Algebra course was statistically significantly higher than the course pass rate for the original online College Algebra course $\left(\chi^{2}(1, N=95)=6.416\right.$; $p=0.011$ ). Furthermore, while the course pass rate for the original online College Algebra course was 22.45 percentage points below the campus-wide College Algebra pass rate during the same time period, the course pass rate for the redesigned online College Algebra course was only 4.39 percentage points below the campus-wide College Algebra pass rate during the same time period. The student attrition rate for the redesigned online College Algebra course, however, was not statistically significantly lower than the student attrition rate for the original online College Algebra course $\left(\chi^{2}(1, N=95)=0.064 ; p=0.801\right)$. 
The grade distributions for all 156 students enrolled during the two-year period were also computed. The course pass rate for the redesigned online College Algebra course $(25.29 \%, N=87)$ was almost double the course pass rate for the original online College Algebra course $(13.04 \%, N=69)$, though the difference was not statistically significant $\left(\chi^{2}(1, N=156)=3.623 ; p=0.057\right)$. And, while the attrition rate for the redesigned online College Algebra course $(27.59 \%, N=87)$ was not statistically significantly lower than the attrition rate for the original online College Algebra course $\left(42.03 \%, N=69 ; \chi^{2}(1\right.$, $N=156)=3.578$; $p=0.059$ ), the attrition rate did drop 14.44 percentage points.

\section{Teaching Presence as a Predictor of Student Success}

Results from a multiple regression analysis indicated that the linear combination of design, time on task, and ACT Math sub-score was statistically significantly related to the overall course percentage $(F(3,53)=8.47, p<0.001)$. The adjusted correlation coefficient was 0.29 indicating that $29 \%$ of the variability in student learning was accounted for by design, time on task, and ACT Math sub-score. All three independent variables were statistically significant predictors of student learning $(p<0.05)$ as seen in Table 5.

Table 5. Summary of Multiple Regression Results

\begin{tabular}{lllll}
\hline Model & $\begin{array}{l}\text { Unstandardized } \\
\text { Coefficient }\end{array}$ & $\begin{array}{l}\text { Standardized } \\
\text { Coefficient }\end{array}$ & $t$ & $p$ \\
\hline Intercept & 20.64 & 12.97 & 1.59 & 0.118 \\
Design & 9.401 & 3.838 & 2.45 & 0.018 \\
Time on Task & 0.11868 & 0.004271 & 2.78 & 0.008 \\
ACT Math Score & 1.6643 & 0.6784 & 2.45 & 0.017 \\
\hline
\end{tabular}

\section{Discussion}

This study examined the impact of instructor-generated video lectures on student performance and student attrition in an online College Algebra course at an open-enrollment university. The original online College Algebra course placed the publisher-generated educational resources in the role of content provider by enabling all publisher-generated learning aids within the online homework system and treating instructor-generated educational materials as supplemental resources. In contrast, the redesigned online College Algebra course enhanced the course instructor's teaching presence by requiring students to complete instructor-generated guided note-taking sheets while watching over 26 hours of instructorgenerated video lectures, treating publisher-generated learning aids as supplemental resources by removing them from within the online homework system.

In studies by Klein (2005) and Aichele, Francisco, Utley, and Wescoatt (2011), students having access to the publisher-generated learning aids embedded within the MyMathLab homework system found the View an Example and Help Me Solve This features to be the most valuable because they provide step-by-step solutions to very similar problems. Aichele et al. (2011) suggested that when students associate procedural learning with success, the belief that mathematics is nothing more than the rote memorization of steps in a process is reinforced. In removing the student-preferred, publisher-generated learning aids from within the online homework system and replacing them with instructor-generated video lectures that provided complete instruction for the algebraic concepts being addressed, procedural learning was deemphasized and the importance of conceptual understanding in the learning of mathematics was highlighted. 
Replacing publisher-generated learning aids with instructor-generated video lectures not only placed a greater emphasis on conceptual understanding, but also positioned the course instructor prominently in the role of content provider, enhancing the course instructor's teaching presence in the online environment. The importance of course design and direct instruction in the online environment was noted by several earlier studies that indicated teaching presence is highly correlated with student perception of learning and critical thinking (Baker, 2010; Hosler \& Arend, 2012; Shea et al., 2003). The results of the study described herein offer additional support to the contention that the course instructor's teaching presence in the online environment and student learning are related. Specifically, while student performance on online homework in the original online College Algebra course was comparable to the student performance on online homework in the redesigned online College Algebra course, students enrolled in the redesigned online College Algebra course performed statistically significantly better on all online and handwritten summative assessments (i.e., quizzes and exams) than students enrolled in the original online College Algebra course.

Given that the students enrolled in the redesigned online College Algebra course performed better on all summative assessments, it is no surprise that the students enrolled in the redesigned course earned a statistically significant higher percentage of passing grades than the students enrolled in the original online College Algebra course. Furthermore, when the overall course grades of all 156 students enrolled during the two-year period were included in the grade distributions, it was noted that the student attrition rate in the course that incorporated the instructor-generated video lectures dropped considerably, an outcome that was also noted by Brecht (2012) in his study of the use of online video lectures as a supplement to a mathematics intensive face-to-face course.

While the results suggest that the amount of time students in the redesigned online College Algebra course spent engaging with the online course content was not statistically significantly greater than the amount of time spent by students in the original online College Algebra course, this difference may be underestimated by the approximation used in measuring the total amount of time on task for the redesigned course. While there is no reason to believe the data collected by the text-based course management system inaccurately measured the amount of time spent working on online assessments, the actual time spent engaging with the video lectures is likely greater than the approximated value since it is known that students frequently pause and rewind the recorded lectures during the process of completing the guided note-taking sheets. And, although the measurement for time on task was computed consistently for each study participant according to the outlined method for their course, the accuracy of time on task, in general, is questionable since the measured value may include logged time during which the student was not actually engaging with the materials. Furthermore, the time on task measurement does not include time spent engaging with publisher-generated learning aids outside of the online homework assignments, time spent reviewing past online assessments, and time spent working offline.

The results of this study also indicate that the design of the online College Algebra course, the amount of time a student spends engaging with the online course content, and the student's ACT Math sub-score, together form a good linear model for predicting student learning as measured by the overall course percentage. That is, to increase the likelihood that a student will successfully pass online College Algebra, not only must students enter the course with an established amount of prerequisite knowledge and a willingness to commit a significant amount of time to learning the course material, but the instructor must also incorporate design techniques and instructional activities that create and sustain a strong teaching presence in the course.

To illustrate the potential importance of the described redesign in online College Algebra, consider the following example. Suppose a student enrolled in the original online College Algebra course that centered around the publisher's text-based multimedia tools had an ACT Math sub-score of 22 (i.e., the course prerequisite for College Algebra at the author's university, effective fall 2015) and spent 61 hours engaging with the online course content (i.e., the average amount of time on task for students 
enrolled in the original online course). The regression model predicts this student's overall course percentage to be $64.5 \%$, resulting in a letter grade of D. As a comparison, suppose a student enrolled in the redesigned online College Algebra course that was organized around instructor-generated video lectures had an ACT Math sub-score of 19 and spent 74 hours engaging with the online course content (i.e., the average amount of time on task for students enrolled in the redesigned online course). The regression model predicts this student's overall course percentage to be $70.4 \%$, resulting in a letter grade of C. This suggests that the described redesign for online College Algebra may assist mathematically weaker students in learning the course content well enough to pass the course.

\section{Limitations}

Since the participants in this study enrolled themselves in the online sections of College Algebra offered by a public university and students cannot be forced to take an online course, there is the possibility of self-selection bias. Given the lack of random assignment to the different course design models, it is possible unmeasured factors influenced the outcomes of this study. Another limitation of this study is that many changes were made to the redesigned online College Algebra course, and hence, interactions between these changes may have occurred. For example, the redesigned online College Algebra course not only incorporated instructor-generated video lectures and the corresponding notetaking sheets, but also removed the publisher-generated learning aids from within the online homework system.

To overcome these issues, a future research design could be implemented in which the selfenrolled students in a single high-enrollment online College Algebra course are randomly assigned to two distinct online courses. While both courses could incorporate the same instructor-generated video lectures and corresponding note-taking sheets, one course could disable the publisher-generated learning aids within the online homework system while the other course could enable the publisher-generated learning aids within the online homework system.

Also, since the online course instructor was also the researcher, unintentional bias may have also influenced the outcomes. The best way to overcome this concern is to repeat the implementation of the redesigned model and observe the results over several more semesters.

\section{Conclusions}

The online College Algebra course offered by the open-enrollment university at the center of this study has a tendency to attract students who are mathematically weaker than the campus average. While these students might experience more success in a College Algebra course in a face-to-face format, for whatever reason they are choosing to enroll in the online course. As with any course-face-to-face or online-it is the responsibility of the instructor to incorporate course design techniques and instructional activities that are likely to encourage student engagement, persistence, and learning. This study suggests instructor-generated video lectures and coordinated note-taking sheets organized within modules may increase success among mathematically unprepared students enrolled in online freshman-level mathematics courses.

Although text-based multimedia tools have much to offer students, instructors of online general studies mathematics courses that are structured around the multimedia tools accompanying course textbooks should proceed with caution. Care must be taken when designing an online course around these text-based multimedia tools to ensure that the instructor is placed prominently in the role of content provider. 


\section{About the Author}

Jennifer S. Hegeman, Department of Computer Science, Mathematics, and Physics, Missouri Western State University

Correspondence concerning this article should be addressed to Jennifer Hegeman, Department of Computer Science, Mathematics, and Physics, Missouri Western State University, 4525 Downs Drive, St. Joseph, MO 64507. Contact: hegeman@missouriwestern.edu.

\section{References}

Aichele, D. B., Francisco, C., Utley, J., \& Wescoatt, B. (2011). Computer-aided college algebra: Learning components that students find beneficial. MathAMATYC Educator, 2(2), 12-19.

ALEKS. (2014). About Us. McGraw-Hill Global Education Holdings, LLC. Retrieved from http://www.aleks.com/about_us

Allen, I. E., \& Seaman, J. (2014). Grade Change: Tracking Online Education in the United States.

Babson Survey Research Group. Retrieved from

http://www.onlinelearningsurvey.com/reports/gradechange.pdf

Anderson, T., Rourke, L., Garrison, D. R., \& Archer, W. (2001). Assessing teaching presence in a computer conferencing context. Journal of Asynchronous Learning Networks, 5(2), 1-17.

Baker, C. (2010). The impact of instructor immediacy and presence for online student affective learning, cognition, and motivation. The Journal of Educators Online, 7(1).

Bleyaert, B., \& Education Partnerships. I. (2010). ACT and College Success. Education Partnerships, Inc. Retrieved from http://files.eric.ed.gov/fulltext/ED537914.pdf

Brecht, H. D. (2012). Learning from online video lectures. Journal of Information Technology Education: Innovations in Practice, 11, 227-250.

Brewer, D. S. (2009). The effects of online homework on achievement and self-efficacy of college algebra students. All Graduate Theses and Dissertations. Paper 407. Retrieved from http://digitalcommons.usu.edu/etd/407

Cascaval, R. C., Fogler, K. A., Abrams, G. D., \& Durham, R. L. (2008). Evaluating the benefits of providing archived online lectures to in-class math students. Journal of Asynchronous Learning Networks, 12(3-4), 61-70.

Chen, X. (2013). STEM Attrition: College Students' Paths Into and Out of STEM Fields (NCES 2014001). National Center for Education Statistics, Institute of Education Services, U.S. Department of Education. Washington, DC. Retrieved from http://nces.ed.gov/pubs2014/2014001rev.pdf

Finnegan, C., Morris, L., \& Lee, K. (2009). Differences by course discipline on student behavior, persistence, and achievement in online courses of undergraduate general education. Journal of College Student Retention: Research, Theory and Practice, 10(1), 39-54.

Fish, W., \& Wickersham, L. (2009). Best practices for online instructors: Reminders. The Quarterly Review of Distance Education, 10(3), 279-284.

Furner, J. M. \& Gonzalez-DeHass, A. (2011). How do students' mastery and performance goals relate to math anxiety? Eurasia Journal of Mathematics, Science, \& Technology Education, 7(4), 227-242. 
Hosler, K. A. \& Arend, B. D. (2012). The importance of course design, feedback, and facilitation: Student perceptions of the relationship between teaching presence and cognitive presence. Educational Media International, 49(3), 217-229.

Jaggars, S., Edgecombe, N., Stacey, G., \& Columbia University, C. (2013). Creating an effective online instructor presence. Community College Research Center, Columbia University. Retrieved from http://files.eric.ed.gov/fulltext/ED542146.pdf

Klein, A. M. (2005). The effects of computer assisted instruction on college algebra students at Texas Tech University (master's thesis). Retrieved from Texas Tech University Electronic Theses and Dissertations Library Database.

Lehman, R., \& Conceição, S. (2014). Motivating and Retaining Online Students: Research-Based Strategies that Work. San Francisco, CA: Jossey-Bass.

MyLab and Mastering. (2014). Break Through to Improving Results. Pearson Higher Education. Retrieved from www.pearsonmylabandmastering.com/northamerica

Nunez-Pena, M. I., Suarez-Pellicioni, M. M., \& Bono, R. R. (2013). Effects of math anxiety on student success in higher education. International Journal of Educational Research, 58, 36-43.

Richardson, M., Abraham, C., \& Bond, R. (2012). Psychological correlates of university students' academic performance: A systematic review and meta-analysis. Psychological Bulletin, 138(2), 353-387. doi:10.1037/a0026838

Shea, P., Pickett, A., \& Pelz, W. (2003). A follow-up investigation of “Teaching Presence” in the SUNY Learning Network. Journal of Asynchronous Learning Networks, 7(2), 61-80.

Simonds, T. A., \& Brock, B. L. (2014). Relationship between age, experience, and student preference for types of learning activities in online courses. Journal of Educators Online, 11(1).

Stone, S. J., \& Chapman, D.D. (2006). Instructor presence in the online classroom. Proceedings of the 2006 Academy of Human Resource Development International Research Conference, Columbus, $\mathrm{OH}$.

Taylor, J. M. (2008). The effects of a computerized-algebra program on mathematics achievement of college and university freshmen enrolled in a developmental mathematics course. Journal of College Reading and Learning, 39(1), 35-53.

WebAssign. (2014). About Us. Advanced Instructional Systems, Inc. Retrieved from https://webassign.com/corporate/about-us/

Xu, D. \& Jaggars, S. (2011). The effectiveness of distance education across Virginia's community colleges: Evidence from introductory college-level math and English courses. Educational Evaluation and Policy Analysis, 33(3), 360-377.

Xu, Y. J., Meyer, K. A., \& Morgan, D. (2008). Piloting a blended approach to teaching statistics in a college of education: Lessons learned. The Journal of Educators Online, 5(2).

Zavarella, C. A. \& Ignash, J. (2009). Instructional delivery in developmental mathematics: Impact on retention. Journal of Developmental Education, 32(3), 2-13. 